\title{
Liver fibrosis is strongly associated with an enhanced level of immunosuppressive tryptophan catabolism independently of HCV viremia in ART-treated HIV/HCV co-infected patients
}

\author{
Mohammad-Ali Jenabian ${ }^{1,2^{*}}$, Ido Kema ${ }^{3}$, Robert Paulino Ramirez ${ }^{4}$, Sahar Saeed ${ }^{5}$, Kathleen Rollet ${ }^{1}$, Kishanda Vyboh', \\ Jean-Carlos Tejada ${ }^{6}$, Norbert Gilmore ${ }^{1,2}$, Marina B Klein ${ }^{1,2}$, Jean-Pierre Routy ${ }^{1,2}$
}

From International Symposium HIV and Emerging Infectious Diseases 2014

Marseille, France. 21-23 May 2013

\section{Background}

HCV infection induces hepatic and extra-hepatic damage that includes kidney and neurocognitive dysfunction. Tryptophan (Trp) is catabolized into immunosuppressive kynurenine (Kyn) by indoleamine 2,3-dioxygenase (IDO) and tryptophan 2,3 dioxegenase (TDO). Increased Trp catabolism measured by Kyn/Trp ratio has been associated with neurocognitive impairment and immune dysfunction in HIV mono-infection. Here, we assessed the contribution of Trp catabolism in HCV/HIV co-infected patients.

\section{Methods}

Plasma samples were collected from ART-treated (HIV RNA $<40$ copies/ml) HCV/HIV co-infected patients with or without liver fibrosis ( $\mathrm{n}=20$ per group), HBV/HIV co-infected patients $(\mathrm{n}=25)$, ART-treated and untreated HIV-mono-infected patients and 30 healthy subjects (HS), $(\mathrm{n}=30$ per group). Furthermore, 17 additional HCV/HIV INF- $\alpha$ /ribavirin treated patients were longitudinally assessed before and 6 months after sustained virological response (SVR). IDO and TDO enzymatic activity (Kyn/Trp ratio) was measured by isotope dilution tandem mass spectrometry. Statistical analyses were performed using Anova, unpaired or paired t-tests and Spearman correlation tests.

\section{Results}

Among HCV/HIV patients, those having fibrosis compared with non-fibrosis had higher APRI scores $(2.48 \pm 0.23$ vs $0.36 \pm 0.018, \mathrm{p}<0.0001)$ and elevated Kyn levels $(2.6 \pm 0.24$ vs. $1.97 \pm 0.15 \mu \mathrm{mol} / \mathrm{L}, \mathrm{p}=0.038)$. For HBV/HIV co-infected, Kyn level was also elevated $(2.1 \pm 0.16 \mu \mathrm{mol} / \mathrm{L})$. The $\mathrm{Kyn} / \mathrm{Trp}$ ratio was equally elevated in all $\mathrm{HCV}$ and $\mathrm{HBV}$ co-infected groups, similar to the untreated mono-infected HIV group. Importantly, HCV/HIV fibrotic and HBV/HIV groups but not the non-fibrotic group had higher Kyn/Trp ratios compared to the ART-treated and HS groups. Unlike HIV viremia, HCV viremia was not correlated with the $\mathrm{Kyn} / \mathrm{Trp}$ ratio. However, in all HCV/HIV co-infected patients, Kyn/Trp ratio was correlated with the APRI score $(p=0.027)$. Successful HCV treatment improved APRI score $(0.89 \pm 0.13$ vs. $0.4 \pm 0.04, p=0.001)$, contrasting with unchanged elevated Kyn/Trp ratios six months after SVR.

\section{Conclusion}

ART-treated HCV/HIV and HBV/HIV co-infected patients presented with elevated immunosuppressive Kyn/Trp ratios when compared to mono-infected HIV-treated patients and reached a ratio similar to the untreated HIV monoinfected patients. In ART-treated patients, liver fibrosis on its own, but not HCV viremia, was associated with an enhanced level of immunosuppressive Tryptophan catabolism. These findings suggest that a necrotico-inflammatory liver syndrome persists even after SVR, and subsequently induces a systemic immune activation by increasing tryptophan catabolism. 


\section{Authors' details}

${ }^{1}$ Chronic Viral IIInesses Service of the McGill University Health Center, Montreal, Quebec, Canada. ${ }^{2}$ Research Institute of the McGill University Health Center, Montreal, Quebec, Canada. ${ }^{3}$ Department of Laboratory Medicine, University Medical Center, Groningen, University of Groningen, The Netherlands. ${ }^{4}$ School of Medicine, Research Department, Universidad Iberoamericana, Santo Domingo, Dominican Republic. ${ }^{5}$ Clinical Research

Solutions, Montreal, Quebec, Canada Division of Hematology, McGill University Health Center, Montreal, Quebec, Canada. Instituto Dominicano de Estudios Virologicos, Santo Domingo, Dominican Republic.

Published: 23 May 2014

doi:10.1186/1471-2334-14-S2-016

Cite this article as: Jenabian et al: Liver fibrosis is strongly associated with an enhanced level of immunosuppressive tryptophan catabolism independently of HCV viremia in ART-treated HIV/HCV co-infected patients. BMC Infectious Diseases 2014 14(Suppl 2):O16.

Submit your next manuscript to BioMed Central and take full advantage of:

- Convenient online submission

- Thorough peer review

- No space constraints or color figure charges

- Immediate publication on acceptance

- Inclusion in PubMed, CAS, Scopus and Google Scholar

- Research which is freely available for redistribution

Submit your manuscript at www.biomedcentral.com/submit 